\title{
A Moment in Time: Leisure and the Manifestation of Purpose
}

\author{
Justin Harmon ${ }^{1} \cdot$ Lauren N. Duffy ${ }^{2}$
}

Received: 27 August 2020 / Accepted: 13 October 2020 / Published online: 16 October 2020

(C) Springer Nature Switzerland AG 2020

\begin{abstract}
There has been little consideration given to understanding the concept of time within leisure. Just what is time when considered as an ordering mechanism of our leisure behaviors? Most leisure research has approached the concept of time through a largely Western, monochronic understanding which emphasizes time for its linear ordering and quantifiable qualities. The dominance of this implicit understanding of time is also notably influenced by pressing ideologies that define Western society, such as neoliberalism, which can distort our personal discourse with our own time: we see it as a commodity - something to be used efficiently and to be invested. What this thoughtpiece aims to do is consider the existential properties of time, particularly the "moment," as an opportunity to "achieve [the] total realization of a possibility" as illustrated by Lefebvre.
\end{abstract}

Keywords Time $\cdot$ Leisure $\cdot$ Purpose $\cdot$ Moments

\section{Introduction}

"There is a wide discrepancy between time as it is lived and time as it is considered."

- Edward T. Hall (1983)

Justin Harmon

harmon@uncg.edu

1 Department of Community and Therapeutic Recreation, University of North Carolina Greensboro, Greensboro, NC 27412, USA

2 Department of Parks, Recreation and Tourism Management, Clemson University, Clemson, SC, USA 
"Time" has always been a central component to understanding leisure. The narrative of modern, industrialized nations with 40-h work weeks led to the emergence of our dualistic view of work and leisure that comprise our lives, and thus, early concepts of leisure were defined by time outside work, instilling the centrality of time in how we understand leisure (Godbey 2016). As a result, most research on time in the field of leisure studies has focused on the use of time, typically through time diaries (Robinson and Godbey 1997) and other self-report time-use studies (Bureau of Labor Statistics 2020; Godbey 2016). Building from this, then, has been the utility function of time where the purposeful use of it is considered an essential ingredient to a life well-lived in the pursuit of the "American Dream" (Hunnicutt 2013).

Time has been implicitly explored through the frameworks of serious leisure (e.g., Stebbins 1992), recreation specialization (e.g., Scott and Shafer 2001), and enduring involvement (e.g., McIntyre and Pigram 1992). In each of these frameworks, time manifests as forms of commitment, or the behavioral components that tie individuals to routines of leisure behavior (habitual use of time) and a level of involvement indicative of devotion to an activity (intentional use of time). Other scholars have looked at the segmented phases of leisure experiences and their effect on future participation (Harmon and Dunlap 2018), as well as the continuation of leisure experiences after participation (Scott and Harmon 2016), both key aspects of understanding the role of temporality, particularly as it relates to continuity in leisure repertoires. Likewise, with the interest in intentional leisure experience design, there has been more recent attention paid to the temporal episodes that occur within experiences and the methods to study these across the duration of an experience (e.g., experiential sampling method; see Ito et al. 2019; Quinlan Cutler et al. 2018; Zajchowski et al. 2017).

Though there is no one guiding theory of time, there has been little consideration given to understanding the concept of time within leisure. Just what is time when considered as an ordering mechanism of our leisure behaviors? Time has been theorized as both absolute (Merrifield 2013) and abstract (Hall 1983), but our internalization of it is often entirely subjective as something that can be transcended (Berdyaev 1938/2009), or in many cases, as something that has control over us (Rose 2017). What this thought-piece aims to do is consider the existential properties of time, particularly the "moment," as an opportunity to "achieve [the] total realization of a possibility" (Lefebvre, as cited in Merrifield 2013, p. 27).

Moments, according to the work of Henri Lefebvre, are "the delirious climax of pure feeling, of pure immediacy, of being there and only there," and a desire to "endure" in the ephemeral properties of bliss, revelation, and connection (Merrifield 2013, p. 28). While moments evaporate as a requirement of its fleeting qualities, their effects can endure. Moments are understood as the opposite of alienation, which is reflected as "absence, a dead moment empty of critical content"; the Lefebvrian moment signifies "presence, a fullness, [being] alive and [feeling] connected" (Merrifield 2013, p. 29; emphasis original). While presence has certainly been explored in leisure through the concept of flow (e.g., Csizszentmihalyi 2008), ruminations in this area have focused solely on absorption into the leisure activity, absent any significant consideration to the temporal component aside from simply "losing track of time." That is, most leisure research has approached the concept of time through a largely Western, monochronic understanding which emphasizes time for its linear ordering and quantifiable qualities. The dominance of this implicit understanding of time is also notably influenced by 
pressing ideologies that define Western society, such as neoliberalism, which can distort our personal discourse with our own time: we see it as a commodity - something to be used efficiently and to be invested. Metaphors are flippantly attributed to the experience of time without any depth of consideration in definition or description as it relates to the temporal aspects of experience: we "speak of it as being saved, spent, wasted, lost, made up, crawling, killed, and running out," but we rarely explore the complexities that lie beneath the surface (Hall 1983, p. 48).

As Hall (1983) stated, "Time is so thoroughly woven into the fabric of existence that we are hardly aware of the degree to which it determines and coordinates everything we do, including the molding of relations with others in many subtle ways" (p. 48). The essential value of time can be found in "the manifestation of purpose" (Berdyaev 1938/ 2009 , p. 99), something often sought through, and attributed to, meaningful leisure experiences. Thus, the moment, in leisure, is the point of departure, the pivotal processing of experience where we make decisions in the existential reckoning of our lives in the pursuit of transcendence. Below, three cases are examined through the lens of Lefebvre's moments in time. Each demonstrate the notion that moments pass, yet the imprint they leave on us can go on to define the trajectory of our lives and meaning in life.

\section{Examining "Moments" in Time}

There are generations of Americans who remember exactly where they were when President John F. Kennedy and Dr. Martin Luther King, Jr. were assassinated, when the space shuttle Challenger blew up, or when the Twin Towers fell on 9/11; all moments that were jarring and decentering to life that followed. Building on Lefebvre's work, Elden et al. (2003) state that a moment not only defines a form, but a form is also defined by it. Moments can redefine or confirm one's trajectory. Moments are recognized through individual-level consciousness, but those recognitions can take place in the broader tapestry of social consciousness and collective memory. That a moment could either confirm, deny, or disrupt routines, understandings, or beliefs, suggests that it can lead to shockwaves that reorder social life, even if only for a finite period of time - but in some instances, permanently. Much like being in a multi-car accident, there is a cascading effect from the point of impact on all involved that can extend beyond just those onsite, especially if the injuries of those involved are serious. The injuries sustained, and the rehabilitation required to follow, or the long-lasting effects of the permanence of injury, can alter the time which is still yet to come. In the moment, a blink of the eye, whole lives can be forever changed.

Just the same, moments can be pivotal and positive in terms of how they reorient life, interests, relationships, goals, and meanings. Moments can be ambiguous, their importance not immediately recognizable until the series of events that follows has completed its evolution or escalation. Elden et al. (2003) state that, "There is no moment except in so far as it embraces and aims to constitute an absolute" (p. 175). But that "absolute" might not be recognized immediately for lack of information or context, might only come into being through reflection on historical events, or may not be understood until the sequences that initiated it, or follow it, are put into place. 
In what follows, we explore the state of altered time through life during the Covid19 pandemic and the moment "it all changed"; the death of George Floyd as the breaking point of public consciousness after centuries of injustice culminating in feelings of "enough"; and the moment when one recognizes their life is no longer lived as their own when there is a loss of control of one's time through incarceration.

\subsection{Altered Time: Life during Pandemic}

The surreality of life in 2020 - both in the United States and across the globe once Covid-19 forced itself on humankind, was quite abrupt even though there were signs indicating we should have been better prepared. The everyday, takenfor-granted "normalcy" of life was disrupted - toppled on its head. In the United States alone, millions lost their jobs; those who did not, in many instances, had to work from home where they were met with competition for their time. For many, it came in the form of children who were now out of school, sent home to continue their "education," albeit with parents playing a significant role in their instruction (Burk et al. 2020).

Still others were not so lucky, as the realization of just what and who was "essential" became very clear (Rose 2020). Those on the "front line" were forced to navigate the precarious circumstances of the new world order as daily mis/information and everevolving updates from scrambling medical professionals and beleaguered governmental bureaucrats tried to keep up with what had become an almost minute-by-minute news cycle, seemingly always two steps behind the best practices for life during a global pandemic. Our lives, almost literally, changed moment-by-moment as new information surfaced. Realization of a "new normal" also came through moments that captured changes in the most mundane aspects of everyday life: scrolling TV listings for live sports and finding none, negotiating a transaction at the post-office through a make-shift protective barrier, or participating in telehealth appointments instead of visiting a doctor's office. All of these examples illustrate Lefebvre's notion that moments can be those events that simply register the possibility of a life that could look, feel, and be, different. However, the case of Covid-19 is not only about the moments that signify the new normal, but in itself became a disrupter of how time is spent, with the oft-used descriptor, "Covid time." With the shake-up in daily routines came a perceived glut of "free time," in large part because most social and recreational outlets and activities were halted for the foreseeable future. Entertainment, edification, and exercise were all now fully our responsibility whether we liked it or not (Simpson 2020; Williams 2020). Slowly, but surely, we were forced to recognize that the hours in our days were our own to put in order and make work for us in the face of global uncertainty. Numerous moments presented themselves to us as opportunities for engagement and action; still others seemed to give us permission to not take advantage of our situations, retreating to the couch to binge-watch Netflix, or engage in passive activities, and not make accommodations to otherwise previously-held healthy leisure routines. Some had few choices due to other health or social forces (Son et al. 2020), and for many, the moments that followed lockdown likely resulted in a sense of isolation, loneliness, or alienation (Palgi et al. 2020). But all were opportunities for enacting agency, for recognizing the potential to "seize the moment," to make the best of a situation that continued to remain unclear. 


\subsection{Historical Time: Pivotal Events that Connect the Past with the Present}

Through the long, cruel, and unjust history of chattel slavery, Jim Crow, segregation, and structural racism in the United States, there have been a series of moments that signaled atrocity and horror and the need for change. Central in this rising awareness of injustice and brutality is the rash of police killings of unarmed, and oftentimes innocent, black men in the twenty-first century (Staggers-Hakim 2016). While public shock and sadness simmered to the top with every black man and woman lost to senseless stateimposed violence, it was the killing of one man, George Floyd, on May 25, 2020, where the anger boiled over in the broader public and a moment, captured in an eight minute and $46 \mathrm{~s}$ video, ignited action. While the Black Lives Matter movement had a significant presence since the murder of Michael Brown on August 9, 2014 (see Rickford 2016), with the death of George Floyd, it took on a new insurgence of power brought on by a public who had finally had enough; the moment for action and change was ripe.

The departures from normal routine brought about by Covid-19 intersected with the moment triggered by Floyd's death; it created the opportunity for people to seize that altered state of time to capitalize on the historical moment and take to the streets in protest (Abbady 2020). For many, out-of-work and enraged by police violence, and without structured outlets for leisure, activism and protest became a renewed forum for solidarity and meaning making - the streets became the surrogate for ball fields, basketball courts, dancefloors, and festivals; leisure blended with social justice to create the forum for revolution (Arora 2013). It is the temporal relations that occur in shared space where "societal sense-making" takes place (Poell 2019, p. 1), the communal processing of generations of injustices in a collective call to action instigated by a pivotal moment in history.

\subsection{Lost Time: Losing Control of one's Freedom through “Doing Time”}

Incarceration is the ultimate form of alienation (Cochran and Mears 2013). There is an old adage that when you go to prison you only "do" two days: the day you go in, and the day you come out. The rest of the time spent behind bars is not yours. Not only does being sentenced to jail or prison alienate the inmate from their family, work, and leisure, but it also alienates them from society - and the self (Barry et al. 2020). While many convicted of crimes may have been living a life of alienation before arrest and sentencing, it is only fully realized once the individual is locked up. Elden et al. (2003) stated that, metaphorically, "The alienated person locks himself in the moment; he makes himself its prisoner" (p. 175); but this is likely literally true as well. Either at the moment of capture or sentencing, but certainly once an inmate crosses into government confinement to serve their sentence, it is a series of moments, beginning with the decision to engage in a crime, through sentencing, to incarceration, where past decisions in life can be seen as part of a greater series of decisions, outlining how one loses control of their own time (Severson et al. 2011).

Prison and jails are the epicenters of unfree time, the ultimate paradox and contradiction where agency is removed, and inmates are subject to the impositions of statesanctioned mandates (Shaw and Elger 2015). The same can be said of leisure in this blended temporal-spatial environment. While inmates have the opportunity to engage 
in certain types of "leisure" due to an excess of "free time," they have little control over much of it, and more often than not, that leisure is used primarily for helping pass time (Johnsen and Johansen 2019). While an individual's initial decision to commit a crime, in most instances, was the key moment in their incarceration, they are constrained in their decision-making ability due to their imprisonment. Moments of opportunity are few and far between, and the onus of moments shifts to maintaining habits and making smart decisions until they are released and given back their agency and ability to respond to future moments and sculpt their lives as they see fit.

\section{Discussion}

Time, in a Western context, is an intentionally "disciplining instrument meant to indoctrinate a particular set of arrangements and values among those operating within its purview" (Saul 2020, p. 53), something that is evidenced equally, but differently, through the Covid-19 and incarceration examples. Frequently, time has the appearance of a "homogenous medium" evoking the endurance properties of humans as they work, socialize, reflect, and recreate, but in reality, time is experienced heterogeneously - as a multitude of series where we have the opportunity to process our thoughts and actions in situ (Bergson 1889/2004). Rojek (2010) said that leisure is shaped by history and that all theories of leisure must be situated in time, something that is captured by the social unrest, activism, and protests related to police brutality.

Yet, often, what is perceived as "free time" is infused with anxiety-inducing properties causing individuals to seek out some form of instrumental or practical structure within which to situate their leisure (Batchelor et al. 2020). In our intentional use of "excess" free time at home during Covid-19, in the justice movements we collectively try to develop through social protest, and in the routines we create for ourselves while in confinement, our decisions in the moment redirect us back to regimented patterns of behavior, that while familiar, if not necessarily potentially comfortable, can also be limiting in their predictability to our personal evolution. As we search for the "the manifestation of purpose" (Berdyaev 1938/2009, p. 99) in our lives through leisure, whatever the context, we must be reminded of the importance of the opportunity to "achieve [the] total realization of a possibility" when presented in the moment (Lefebvre, as cited in Merrifield 2013, p. 27).

\section{Conclusion}

Leisure research is uniquely suited to explore the complexities and intricacies of human experience and behavior and its resulting impact on identity, perception, and potential. While the field has explored the temporality of leisure experiences for more than half a century (cf. Clawson and Knetsch 1966), there has been scant effort in the dissection of the units of experience which are often richly rooted in histories, both personal and social. Related, the sociopsychological processing of experience is inextricable from time, and therefore, there must be a reconstituted effort to investigate how moments in time not only define the form of a leisure experience, but how the form of leisure is also defined by time (Elden et al. 2003). 
Phenomenological investigation and oral histories, common methodologies in leisure studies, are apt for generating more intimate knowledge of the micro-temporal moments in leisure. Leisure scholars can approach investigations of time, particularly the moment, by placing more emphasis on points of origin, integral instances, realizations, calls-to-action, ultimatums, and the role of personal responsibility and accountability in leisure. Some expedient examples of the exploration of a leisure moment could be the point when one begins to feel a sense of accomplishment or competence (e.g., breaking a personal record, learning to play the guitar capably), or when one reaffirms their purpose (e.g., seeing the sunrise over a lake, being acknowledged for one's contributions). Moments are not static, and they are not uniform in their duration, but they have the potential to be life-changing, and it is the duty of the field of leisure studies to understand how.

As a final posit, this paper makes an explicit call for more attention to be paid to the concept of time within leisure research. Simply, researchers interested in self-realization through leisure should revisit assumptions regarding time. This paper approached time through a Lefebvrian lens using his theory of moments, however, future research can draw from a range of philosophers, theoretical physicists, and theologists concerned with time, purpose, and meaning making in life.

\section{References}

Abbady, T. (2020). How to protest safely in a pandemic. The Washington Post. Retrieved from: https://www. washingtonpost.com/lifestyle/wellness/how-to-protest-safely-in-a-pandemic/2020/06/02/8de7cf8c-a51511 ea-b619-3f9133bbb482_story.Html.

Arora, P. (2013). Usurping public leisure space for protest. Social activism in the digital and material commons. Space and Culture, 18(1), 55-68.

Barry, L. C., Coman, E., Wakefield, D., Trestman, R. L., Conwell, Y., \& Steffens, D. C. (2020). Functional disability, depression, and suicidal ideation in older prisoners. Journal of Affective Disorders, 266, 366373.

Batchelor, S., Fraser, A., Whittaker, L., \& Li, L. (2020). Precarious leisure: (re)imagining youth, transitions and temporality. Journal of Youth Studies, 23(1), 93-108.

Berdyaev, N. (1938/2009). Solitude \& society. New York: Semantron Press.

Bergson, H. (1889/2004). Time and free will: An essay on the immediate data of consciousness. Eastford: Martino Fine Books.

Bureau of Labor Statistics. (2020). American Time Use Survey-2019 results. Retrieved from https://data.bls. gov/timeseries/TUU10101AA01013585

Burk, B. N., Mausolf, A. P., \& Oakleaf, L. (2020). Pandemic motherhood and the academy: A critical examination of the leisure-work dichotomy. Leisure Sciences. https://doi.org/10.1080/01490400.2020. 1774006.

Clawson, M., \& Knetsch, J. L. (1966). Economics of outdoor recreation. Baltimore: The John Hopkins Press.

Cochran, J. C., \& Mears, D. P. (2013). Social isolation and inmate behavior: A conceptual framework for theorizing prison visitation and guiding and assessing research. Journal of Criminal Justice, 41(4), 252261 .

Csizszentmihalyi, M. (2008). Flow: The psychology of optimal experience. New York: Harper.

Elden, S., Leba, E., \& Kofmon, E. (2003). History, time and space. In H. Lefebvre (Ed.), Key writings (pp. 161-214). London: Continuum.

Godbey, G. (2016). Trends in time for leisure. In G. J. Walker, D. S. Scott, \& M. Stodoloska (Eds.), Leisure matters: The state and future of leisure studies. Urbana: Sagamore-Venture.

Hall, E. T. (1983). The dance of life: The other dimension of time. Norwell: Anchor Press.

Harmon, J., \& Dunlap, R. (2018). The temporal phases of leisure experience: Expectation, experience and reflection of leisure participation. Leisure Sciences, 40(5), 326-342. https://doi.org/10.1080/01490400. 2016.1274246. 
Hunnicutt, B. K. (2013). Free time: The forgotten American dream. Philadelphia: Temple University Press.

Ito, E., Walker, G. J., \& Kono, S. (2019). A comparison of immediate and retrospective affective reports in leisure contexts. Journal of Leisure Research, 50(1), 48-55.

Johnsen, R., \& Johansen, C. B. (2019). Serving time: Organization and the affective dimension of time. Organization, 26(1), 3-19.

McIntyre, N., \& Pigram, J. J. (1992). Recreation specialization re-examined: The case of vehicle-based campers. Leisure Sciences, 14, 3-15.

Merrifield, A. (2013). Henri Lefebvre: A critical introduction. London: Routledge.

Palgi, Y., Shria, A., Ring, L., Bodner, E., Avidor, S., \& Bergman, Y. (2020). The loneliness pandemic: Loneliness and other concomitants of depression, anxiety and their comorbidity during the Covid-19 outbreak. Journal of Affective Disorders, 275, 109-111.

Poell, T. (2019). Social media, temporality, and the legitimacy of protest. Social Movement Studies. https://doi. org/10.1080/14742837.2019.1605287.

Quinlan Cutler, S., Doherty, S., \& Carmichael, B. (2018). The experience sampling method: Examining its use and potential in tourist experience research. Current Issues in Tourism, 21(9), 1052-1074.

Rickford, R. (2016). Black lives matter toward a modern practice of mass struggle. New Labor Forum, 25(1), $34-42$.

Robinson, J. P., \& Godbey, G. J. (1997). Time for life: The surprising ways Americans use their time. State College: Penn State University Press.

Rojek, C. (2010). The labour of leisure: The culture of free time. London: Sage.

Rose, J. (2017). "Never enough hours in the day": Employed mothers' perceptions of time pressure. Australian Journal of Social Sciences, 52(2), 116-130.

Rose, J. (2020). Biopolitics, essential labor, and the political-economic crises of Covid-19. Leisure Sciences. https://doi.org/10.1080/01490400.2020.1774004.

Saul, R. (2020). Temporality and inequity: How dominant cultures of time promote injustices in schools. Review of Education, Pedagogy, and Cultural Studies, 42(1), 49-69.

Scott, D., \& Harmon, J. (2016). Extended leisure experiences: A sociological conceptualization. Leisure Sciences, 38(5), 482-488.

Scott, D., \& Shafer, C. S. (2001). Recreation specialization: A critical look at the construct. Journal of Leisure Research, 33(3), 319-343.

Severson, M. E., Bruns, K., Veeh, C., \& Lee, J. (2011). Prisoner reentry programming: Who recidivates and when? Journal of Offender Rehabilitation, 50(6), 327-348.

Shaw, D., \& Elger, B. (2015). Improving public health by respecting autonomy: Using social science research to enfranchise prison populations. Preventative Medicine, 72, 21-23.

Simpson, B. (2020). Mass hysteria, manufacturing crisis and the legal reconstruction of acceptable exercise during a pandemic. Leisure Sciences. https://doi.org/10.1080/01490400.2020.1774002.

Son, J. S., Nimrod, G., West, S. T., Janke, M. C., Liechty, T., \& Naar, J. J. (2020). Promoting older adults' physical activity and social well-being during Covid-19. Leisure Sciences. https://doi.org/10.1080/ 01490400.2020 .1774015 .

Staggers-Hakim, R. (2016). The nation's unprotected children and the ghost of Mike Brown, or the impact of national police killings on the health and social development of African American boys. Journal of Human Behavior in the Social Environment, 26(3-4), 390-399.

Stebbins, R. A. (1992). Amateurs, professionals, and serious leisure. Buffalo: McGill Queen's University Press.

Williams, D. J. (2020). From gym rat to rock star! Negotiating constraints to leisure experience via a strengths and substitutability approach. Leisure Sciences. https://doi.org/10.1080/01490400.2020.1773979.

Zajchowski, C. A., Schwab, K. A., \& Dustin, D. L. (2017). The experiencing self and the remembering self: Implications for leisure science. Leisure Sciences, 39(6), 561-568.

Publisher's Note Springer Nature remains neutral with regard to jurisdictional claims in published maps and institutional affiliations. 